\title{
Component Incompatible
}

National Cancer Institute

\section{Source}

National Cancer Institute. Component Incompatible. NCI Thesaurus. Code C63022.

A component required for the proper functioning of a device is not compatible with other components or subassemblies of a device, thus compromising the intended function of a device. 